\title{
Synergistic interactions between fire and browsing drive plant diversity in a forest understory
}

Foster, C.N. (corresponding author, claire.foster@anu.edu.au) $)^{1}$

Barton, P.S. (philip.barton@anu.edu.au) ${ }^{1}$

Sato, C.F. (chloe.sato@anu.edu.au) $)^{1,2}$

MacGregor, C.I. (christopher.macgregor@anu.edu.au) $)^{1,2,3}$

Lindenmayer, D.B. (david.lindenmayer@anu.edu.au) 1,2,3

${ }^{1}$ Fenner School of Environment and Society, The Australian National University, 141

Linnaeus Way, Acton, ACT, 2601, Australia;

${ }^{2}$ Australian Research Council Centre of Excellence for Environmental Decisions and the

National Environmental Research Program Environmental Decisions Hub, The Australian

National University, 141 Linnaeus Way, Acton, ACT, 2601, Australia;

${ }^{3}$ The Long Term Ecological Research Network, The Australian National University, 141

Linnaeus Way, Acton, ACT, 2601, Australia

Printed journal page estimate: 6400 words (8 pages), 2 tables (0.4 pages), 4 figures (1.6 pages), total 10 pages. 


\section{$1 \quad$ Abstract}

2 Questions: Does browsing by large herbivores affect forest understory diversity by

3 modifying assemblage dominance? Does fire interact with browsing to affect forest

4 understory diversity? Does this interaction occur via a numerically-mediated or functionally-

5 moderated pathway?

6 Location: Booderee National Park, Jervis Bay Territory, south-eastern Australia

7 Methods: We tested the interactive effects of fire and browsing by native herbivores on 8 understory plant diversity using a randomised blocked experiment in an open eucalypt forest.

9 We monitored the percentage cover of every vascular plant species in 24 sites over four 10 experimental blocks. We applied a different treatment to each of the six sites in the four 11 blocks. Treatments were a factorial combination of three levels of herbivory treatment (open, 12 partial exclosure, full exclosure) and two levels of prescribed fire treatment (burnt, unburnt).

13 Results: Browsing increased plant community dominance and reduced evenness and 14 diversity, but only in burnt sites. Heavy browsing following fire created an understory dominated by an unpalatable, fire resistant fern species (bracken, Pteridium esculentum). This

16 fire-browsing interaction was driven by both numerically-mediated and functionally-

17 moderated pathways: Fire both increased local browsing intensity, and amplified the per-unit 18 effect of herbivores on the plant community.

19 Conclusions: The altered competitive environment after fire, combined with heavy post-fire browsing created a depauperate understory, dominated by bracken fern. The ability of bracken to supress the establishment of other plants means that, once established, this fern-

22 dominated understory may be difficult to reverse. Our results demonstrate the key role of

23 fire-browsing interactions in forest vegetation dynamics and highlight the importance of integrating large herbivore management with fire planning in forest ecosystems. 
Key words

27 Alternate stable states; Browsing; Community structure; Dominance; Disturbance interaction; Eucalyptus forest; Herbivory; Macropod; Plant diversity; Pteridium esculentum; Understory

Nomenclature

Robinson (1991)

\section{Running Head}

34 Fire-browsing interactions

\section{Introduction}

37 Herbivory is a core process driving the structure and diversity of plant communities in many ecosystems worldwide (Milchunas et al. 1988; Hester et al. 2006; Borer et al. 2014). In forested systems, selective browsing by large herbivores can have transformative effects, altering canopy tree species dominance and driving cascading effects through the rest of the ecosystem (Royo \& Carson 2006; Holm et al. 2013; Côté et al. 2014). Browsing has also been shown to exert strong effects on forest understory vegetation. However, there is little agreement among studies about whether browsing enhances or reduces the diversity of forest understory plants. Positive effects (Royo et al. 2010a), negative effects (Rooney \& Waller 2003; Jenkins et al. 2014), and no effect (Kerns et al. 2011) of browsing on understory plant diversity have all been reported, with discrepancies between studies attributed to differences in herbivore densities, ecosystem productivity, disturbance history and other site-dependent variables (Hester et al. 2006; Royo et al. 2010a).

While the net effects of herbivory on plant diversity are variable, it has been suggested that most responses can be explained by effects on plant species dominance 
51 (Hester et al. 2006). In systems where herbivores selectively feed on dominant plant species, they will reduce assemblage dominance, and increase resource availability for competitively inferior plants, thereby increasing diversity (Côté et al. 2004; Hester et al. 2006). However, when the dominant species are unpalatable, herbivores will have the opposite effect. A number of recent studies from grassland systems have supported this hypothesis, finding that the effects of herbivory on ground-level light availability (which is driven by the abundance of dominant species), consistently explained herbivory effects on plant diversity, despite the sites having a wide range of abiotic conditions and disturbance histories (Borer et al. 2014; Eby et al. 2014; Koerner et al. 2014).

Understanding the effects of grazing and browsing can be useful for predicting the outcomes of management interventions (Hester et al. 2000). Such predictions, however, are complicated by the fact that herbivory can interact strongly with other episodic disturbance events (e.g. fire, timber harvest, drought; Royo \& Carson 2006; Wisdom et al. 2006). These interactions can produce vastly different outcomes than would be predicted from studies of individual effects, and can lead to unintended management outcomes (Tylianakis et al. 2008). Ecological disturbances can interact via two main pathways: an interaction chain (a numerically-meditated process), and an interaction modification (a functionally-moderated process) (Didham et al. 2007). In the context of disturbance-grazing interactions, a numerically-mediated interaction could occur through disturbance changing the local abundance of herbivores, in turn affecting vegetation. A functionally-moderated interaction would occur if disturbance modified the per unit effect of herbivores on vegetation. Both these interaction pathways are commonly described in studies of fire-grazing interactions, although they are not often explicitly identified as such. For example, patch burning of grasslands can initiate a numerically-mediated fire-grazing interaction; fire stimulates fresh growth which attracts large herbivores (Allred et al. 2011). The resulting 
concentration of herbivores increases local grazing intensity, while reducing it elsewhere,

which increases vegetation heterogeneity (Fuhlendorf et al. 2006). By modifying the competitive interactions among plant species, or selectively acting on some plant traits, fire can also have a functionally-moderated effect on plant responses to herbivory. For example, in a North American mesic grassland, annual burning amplified the negative effect of grazing exclusion on plant diversity (Eby et al. 2014). This was due to the dominant grass species in the system being both a post-fire increaser and highly palatable. These two functional traits gave this grass species a competitive advantage following fire and allowed it to dominate the plant community in the absence of herbivores (Eby et al. 2014).

As disturbances can interact with the life history traits of organisms, as well as with each other, predicting the outcomes of disturbance interactions is problematic, even if plant traits are well understood (Royo \& Carson 2006). Therefore, understanding such interactions requires manipulative experiments that are able to test the non-additive effects of these processes (Didham et al. 2007; Tylianakis et al. 2008). Manipulative tests of the interactive effects of herbivory and disturbance have become reasonably common in grassland systems (e.g. Fuhlendorf et al. 2006; Collins \& Calabrese 2012; Koerner \& Collins 2014), but remain rare in forested systems (Wisdom et al. 2006; Royo et al. 2010a). The high densities of large herbivores in many forests worldwide (Côté et al. 2004), and the prevalence of active fire management in forest ecosystems (Stephens \& Ruth 2005; Boer et al. 2009), mean that improving our understanding of the effects of fire-browsing interactions on vegetation dynamics is of high importance for the management of forest ecosystems (Wisdom et al. 2006).

We studied the effects of fire $\times$ browsing interactions on plant diversity in a temperate forest understory, testing the hypothesis that effects on plant diversity would be similar to those described for grassland ecosystems. Our study had three main predictions: (1) That 
101 browsing by large herbivores would affect plant diversity by modifying assemblage dominance. Specifically, as the dominant understory species in our study system was of low palatability (Pteridium esculentum, Di Stefano \& Newell 2008; Fletcher et al. 2011), we

104 predicted that browsing would increase assemblage dominance and reduce diversity. We also

105 predicted that: (2) fire would amplify the effects of browsing on plant diversity, and that (3)

106 this interaction would occur via both numerically-mediated and functionally-moderated

107 pathways. The numerically-mediated effect would be driven by more herbivores browsing in

108 burnt sites, while the functionally-moderated effect would be driven by fire amplifying the

109 effects of herbivory on P. esculentum dominance.

\section{Methods}

\section{Study site}

113 We conducted this study in Booderee National Park (BNP); a $\sim 600$ ha peninsula in south-

114 eastern Australia ( $35^{\circ} 10^{\prime} \mathrm{S}, 150^{\circ} 40^{\prime} \mathrm{E}$, Fig. 1). The most widespread vegetation type in the

115 park is open eucalypt forest (Taws 1998). This forest type is dominated by Eucalyptus

116 pilularis, Corymbia gummifera and E. botryoides in the overstory ( $>10 \mathrm{~m})$, Banksia serrata,

117 Acacia longifolia and Monotoca elliptica in the midstory $(2-10 \mathrm{~m})$ and Lomandra longifolia

118 and P. esculentum in the understory $(<2 \mathrm{~m})$ (Taws 1998; Lindenmayer et al. 2008).

119 An intensive baiting program targeting the introduced red fox (Vulpes vulpes) has

120 been in place within the park since 1999 to protect native small mammal species from

121 predation (Dexter et al. 2012). As hunting has been long discontinued and dingoes (Canis

122 lupus dingo) now occur only rarely in the park, the removal of foxes means that predation

123 pressure on herbivores is low (Lindenmayer et al. 2014). Since the removal of foxes, there

124 has been a tenfold increase in the numbers of native macropod herbivores within the park

125 (Dexter et al. 2012; Lindenmayer et al. 2014). The most common of these macropods are the 
swamp wallaby, Wallabia bicolor, a generalist browser, and the eastern grey kangaroo,

127 Macropus giganteus, a grazer (Davis et al. 2008; Dexter et al. 2013). Small-scale exclosure

128 trials have indicated that the current high abundance of these herbivores could be driving a

129 decline in some plant species (Dexter et al. 2013).

\section{Study design}

131 We quantified the interactive effects of fire and large herbivores on understory plant diversity

132 using a randomised, blocked experiment. We examined three levels of herbivory treatment

133 and two levels of burning treatment in a factorial design (Fig. 1). We replicated each of these

134 six treatment combinations across four experimental blocks to give a total of 24 sites. For the 135 herbivory treatments, we manipulated the density of macropods within $25 \times 25 \mathrm{~m}$ plots using

136 exclosure fences to produce three levels of herbivory: full herbivory (open treatment),

137 intermediate herbivory (partial treatment - plots were fenced but gates opened and closed at

138 two month intervals to simulate lower browsing pressure), and no herbivory (exclosure

139 treatment). We constructed exclosure fences in June 2012 using $1.1 \mathrm{~m}$ tall feral-proof stock

140 fencing, which we found to be effective at excluding macropods (see results). For the burning

141 treatments, we conducted $50 \times 50 \mathrm{~m}$, low severity burns across half of the herbivore

142 treatment sites in August 2012. Burns removed approximately 95\% of understory vegetation

143 from the site and did not reach canopy foliage (tree scorch height $1.5-4 \mathrm{~m}$ ).

\section{Data collection}

145 We surveyed understorey vegetation prior to treatment implementation in April/May 2012

146 (austral autumn) and repeated surveys three months after burning, and then every six months

147 until May 2014. To capture variation within each site, we sampled vegetation using four

148 small quadrats, rather than one large quadrat in each site. We placed four $3 \times 3 \mathrm{~m}$ quadrats at

149 fixed locations in each site, with one quadrat in each of the four quarters of the site, ensuring 
150 each was at least $1.5 \mathrm{~m}$ from the fence. For each quadrat, we visually estimated the projective

151 cover of each vascular plant species, using the same observer for all estimates. Prior to any

152 data processing, we averaged the cover values of each plant species across the four quadrats

153 to give one value for the $36 \mathrm{~m}^{2}$ area sampled in each site. We used these site-level data to

154 calculate four standard metrics of community diversity: species richness (species/ $36 \mathrm{~m}^{2}$ ),

155 species diversity (Simpson's reciprocal index $-1 / D$ ), evenness (Simpson's evenness $-E_{1 / D}$ ),

156 and assemblage dominance (Berger-Parker index - d) (Magurran 2004).

157 We surveyed site use by macropod herbivores by counting their scats along two $25 \times$

$1582 \mathrm{~m}$ transects $\left(100 \mathrm{~m}^{2}\right)$ in each site, summing counts to give one overall count per site. We

159 surveyed transects every two months from August 2012 to May 2014. We removed scats

160 from transects after each survey to avoid double counting. For analysis, we summed the two

161 scat counts preceding each vegetation survey to give an estimate of the average level of

162 herbivore activity in a site leading up to each sampling event.

\section{Data analysis}

164 We tested the effects of herbivory, fire and their interaction on plant species richness,

165 diversity, evenness and dominance using linear mixed-models (LMMs) in R (R Core Team

166 2013). The full model for these analyses included the fixed effects of herbivory $\times$ fire $\times$ time,

167 plus the pre-treatment value (to account for any pre-existing differences between sites), and

168 random effects of block/site. Instead of the categorical herbivory treatments, we used the scat

169 counts at each site as our measure of herbivory. This allowed us to account for variation in

170 herbivore pressure both between and within levels of the herbivore exclosure treatments, and

171 also to test whether the relationship between herbivore pressure and plant diversity metrics

172 differed between burnt and unburnt sites (i.e. whether there was a functionally moderated

173 interaction). Prior to inclusion in the model as a fixed effect, scat count data were natural $\log$

174 (ln) transformed to reduce skew, and standardised by centring, and dividing by two standard 
175 deviations to allow comparison of the main effects of fire and herbivory and aid in interpretation of interaction terms (Gelman \& Hill 2007). After checking the fit of the full models by inspecting residual plots (Zuur et al. 2009), we used the "dredge" function in the package "MuMIn" (Barton 2014) to rank all possible subsets of the full model, based on

179 minimising Akaike's Information Criterion, corrected for small sample sized (AICc)

180 (Burnham \& Anderson 2002).

As our study included repeated measures at sites, we tested for temporal autocorrelation between repeated measures at sites using the "acf" function in R (R Core Team 2013). Autocorrelation for all variables was low, and including a first-order autoregressive correlation structure on the random effects did not improve the fit of the LMMs. Therefore, we did not include correlation structures in our final models (Pinheiro \& Bates 2000). We also considered fitting the species richness data with a generalised linear mixed-model (GLMM), with Poisson errors, which is often used for count data. However, this was not used in the final analysis as the characteristics of a Poisson distribution (skewed distribution and heteroscedasticity) were not evident in our data (Zuur et al. 2009), and a trial

190 GLMM showed poor fit at the extremities when compared with the LMM. pathway, we tested whether fire increased herbivore activity (as measured from scat counts) within the different exclosure treatments. We used GLMM with a Poisson error distribution

194 and a log-link function for this analysis, with exclosure treatment $\times$ fire $\times$ time as fixed

195 effects and block/site as random effects. As very low scat counts in exclosure treatments $(\overline{\mathrm{X}}=$ $1961.78 \pm 0.53,59 \%$ of counts $=0$ ) led to complete separation of factor combinations (Gelman \& 197 Hill 2007), the exclosure treatment was excluded from this analysis. Scat count data were

198 found to be over-dispersed, which we accounted for by including an observation-level 199 random effect in our model (Harrison 2014). 

combinations both pre- (May 2012) and post-treatment (May 2014), using nonparametric blocked multi-response permutation procedures (MRBP, McCune \& Grace 2002) in PC-ORD

203 (McCune \& Mefford 2006). We excluded rare species (those occurring at 2 or fewer sites)

204 from the site $\times$ species matrix and relativized abundances within sites, prior to analysis

205 (McCune \& Grace 2002). If MRBP indicated significant differences in species composition among treatments, we then used indicator species analysis (Dufrene \& Legendre 1997) to identify individual species associated with the different treatments. We used the function "multipatt” in the R package "indicspecies" (De Cáceres \& Legendre 2009), which allows the identification of species associations with combinations of groups (treatments) rather than

210 just a single group (De Cáceres et al. 2010). We set the maximum number of groups

211 (treatment combinations) to be combined to three as this allowed us to identify associations

212 with both individual treatment combinations, as well as with complete factors in the factorial 213 design. We accounted for the blocked structure of sites by constraining permutations within, 214 rather than among blocks. Significance was determined from 9999 permutations of the data.

216 Results

\section{Effect of browsing and fire on plant diversity metrics}

218 We detected 111 understory plant species over five surveys in the two-year study period 219 (Appendix S1). In the top-ranked LMMs, fire modified the effect of herbivory on plant 220 community diversity, evenness, and dominance and this interaction was consistent across time (Table 1, Fig. 2, Appendix S2). Plant species diversity, evenness and dominance were not related to herbivore activity on unburnt sites, but burnt sites had lower community diversity and evenness and higher assemblage dominance as herbivore activity increased

224 (Table 1, Fig. 2). This indicates a functionally moderated interaction. The difference in 
community diversity and evenness between burnt and unburnt sites varied through time and was highest 15 months post-fire. In contrast, the highest-ranked model for assemblage dominance indicated that the effect of fire was consistent across time; at high levels of herbivory, the relative abundance of the dominant species was $30 \%$ higher in burnt than unburnt sites (Fig. 2). This increase in assemblage dominance was driven by P. esculentum, which comprised approximately $70 \%$ of the vegetation cover in burnt-open sites, but less than $40 \%$ in burnt and unburnt exclosure sites (Fig. 3). In contrast to the other diversity metrics, none of the models for species richness with $\Delta \mathrm{AICc}<2$ included the herbivory $\times$ fire interaction (Appendix S2), and the effects of fire were short-term, with species richness of

234 burnt sites returning to the level of unburnt sites within 15 months (Table 1).

\section{Effect of fire on herbivore activity}

Fire affected herbivore activity levels, with both the first and second ranked models showing that scat counts were higher on burnt than unburnt sites (Table 2), indicating a numerically-mediated interaction between fire and herbivory. In the first-ranked model, this effect was consistent across time, but in the second-ranked model, this difference was significant only in the period from three to nine months post-fire, where counts in burnt sites were more than double those in unburnt sites (Table 2, Fig. 4).

\section{Effect of browsing and fire on plant species composition}

Species composition did not differ among experimental treatments prior to treatment

244 implementation in May 2012 (MRBP, $P=0.15$ ). However, by May 2014, species

245 composition differed significantly among treatments (MRBP, $P=0.004)$. Pairwise

246 comparisons revealed that burnt-open sites had significantly different species composition to

247 all other treatment combinations (all $P<0.05$ ). Burnt partial and burnt exclosure sites also

248 differed significantly in composition $(P=0.03)$. 
Indicator species analysis identified six individual species that were associated with the experimental treatments, each of which was positively associated with three of the treatment combinations (all $P<0.05$, Appendix S1). The fern $P$. esculentum was positively associated with both burnt and unburnt open sites, as well as burnt partial sites. Conversely, the grass Themeda australis and the herb Galium propinquum were associated with both burnt and unburnt exclosure treatments, as well as unburnt partial treatments. A further three species were associated with burnt exclosure treatments but differed in their other associations; the small tree Synoum glandulosum was also associated with burnt partial and unburnt exclosure sites, the sub-shrub Marsdenia suavolens was also associated with unburnt exclosure sites and burnt open sites, and another small tree Persoonia linearis was associated with all burnt treatments.

\section{Discussion}

262 We tested plant diversity responses to browsing and the fire-browsing interaction using a manipulative experiment in a temperate forest understory. As predicted, where browsing

264 increased plant community dominance, it reduced plant diversity and evenness. Prescribed

265 fire interacted strongly with browsing, with herbivore activity affecting these measures of 266 plant diversity only in burnt sites. This fire-browsing interaction was generated through a combination of numerically-mediated and functionally-moderated pathways; fire both increased herbivore activity levels, and increased the per-unit effect of herbivores on the plant community.

\section{Effect of browsing and fire}

Browsing had little effect on the plant community in the absence of fire, but browsing in

272 burnt environments increased community dominance, reduced plant community evenness and 273 diversity, and altered species composition. Specifically, browsing in burnt environments 
increased the dominance of the fern $P$. esculentum and reduced the abundance of a number of palatable grasses and herbs. This pattern was consistent with previous studies where plant diversity responses to grazing depended on the effect of grazing on the dominant plant species (Mathisen et al. 2010; Royo et al. 2010a; Borer et al. 2014). As suggested by Royo et al. (2010a), the variable effect of browsing on the dominant plant species can potentially explain the wide range of reported effects of large herbivores on forest plant diversity. In systems where large herbivores have been at high abundances for extended periods, understories are largely dominated by a few unpalatable species; this is the case in many forested systems of North-America (Tremblay et al. 2006; Rooney 2009) and Europe (Kirby 2001) where deer are highly abundant. In such systems, continued browsing maintains the dominance of unpalatable species, while herbivore exclusion can allow palatable species to recover, thereby increasing plant species richness and evenness. In systems where large herbivores are not highly abundant, browsing may help to maintain understory diversity by reducing the dominance of fast-growing palatable species, particularly following disturbance (Royo et al. 2010a).

Despite having strong effects on plant community diversity and evenness after fire, we found that browsing did not affect plant species richness, either with or without burning. Mathisen et al. (2010) reported a similar result for moose browsing in Swedish pine forest.

292 This may be because much of the vegetation in both the study by Mathisen et al. (2010) and 293 in our study was comprised of shrubs (Appendix S1). Browsing is often not lethal for 294 established individuals of woody plant species (Hester et al. 2006). Thus, in forest systems with woody understories, browsing will affect the relative cover of different species more strongly than the relative number of individuals. In addition, as shrubs are slow-growing and

297 long-lived compared with many herbs and grasses (McFarland 1998), the two-year time 
298 frame of our study may have been insufficient for differences in colonisation and extinction

299 rates to become apparent.

\section{$300 \quad$ Interaction pathways}

301 The stronger effect of herbivory on vegetation after burning occurred both via numerically-mediated and functionally-moderated pathways. Burning both increased the herbivore activity at a site (Fig. 4), and increased the per unit effect of herbivore activity on the vegetation (Fig. 2). The attraction of large herbivores to recently burnt patches has been well documented in grassland ecosystems (Allred et al. 2011), and has also been shown for some forest-dwelling ungulates (Fisher \& Wilkinson 2005). However, previous studies of macropod herbivores following fire have found little effect of large wildfires on macropod densities (Garvey et al. 2010; Arthur et al. 2012). These contrasting results indicate that firebrowsing interactions driven by the attraction of herbivores to burnt areas may be more likely to occur following small, patchy fires (as occurs with prescribed burns), than following large-

311 scale wildfires. The effects of prescribed fire on browsing intensity should therefore be considered in fire planning in these systems, especially where herbivores are particularly

313 abundant.

314 The greater per-unit effect of herbivores on vegetation in burnt than in unburnt sites was

315 likely due to the competitive release of $P$. esculentum following fire. After fire (and other

316 disturbances), Pteridium species can rapidly regenerate from below-ground rhizomes and

317 dominate recently disturbed environments (Skre et al. 1998; Spencer \& Baxter 2006).

318 However, in the absence of further disturbance, the dominance of P. esculentum usually

319 declines with time since fire, as other plants become more established (Spencer \& Baxter 320 2006). In our study, browsing maintained assemblage dominance two years after fire, with $P$.

321 esculentum comprising almost $70 \%$ of understory vegetation cover in burnt, browsed (open) sites, compared with less than $40 \%$ in burnt, un-browsed sites (Fig. 3). The dominance of $P$. 
esculentum could have important consequences for the ability of the vegetation to recover to its pre-fire state, as P. esculentum can form a shade canopy which supresses the establishment of other plants (Tolhurst \& Turvey 1992). Therefore, our results suggest that heavy browsing after prescribed fire may lead to an understory dominated by a few fire- and browsingresistant species, which could be difficult to reverse.

An understory dominated by browse- and fire-resistant plants was suggested by Wisdom et al. (2006) as a likely outcome of low serverity forest fires under moderate or high herbivory. Previous studies of the individual effects of chronic herbivory (Rooney 2001) and reoccurring fire (Spencer \& Baxter 2006) have documented transitions towards depauperate understories dominated by ferns (Dennestaedtia and Pteridium respectively). Our study, and an earlier pilot study (Dexter et al. 2013), show that, in concert, fire and herbivory can have synergistic effects, creating a depauperate, fern-dominated understory over a relatively short time period. Our results also show that at low levels of herbivory, differences in vegetation diversity between burnt and unburnt sites are small. Therefore, in forests where predation by foxes and dingoes keeps macropod herbivores at low densities, fire-browsing interactions may have limited effects on vegetation diversity.

Although the timeframe of our study means we cannot predict whether the effects of these

340 fire-browsing interactions will persist in the long-term, alternate stable states driven by

341 chronic herbivory have been documented from a range of forest ecosystems worldwide (Royo

342 \& Carson 2006; Raffaele et al. 2011; Tanentzap et al. 2011; Hidding et al. 2013). These

343 systems are characterised by understories with low floristic diversity which are dominated by

344 a few, unpalatable species (de la Cretaz \& Kelty 1999; Horsley et al. 2003). Once such states

345 have developed, legacy effects can prevent the recovery of plant diversity, even if herbivore

346 densities are reduced (Royo et al. 2010b). Preventing the development of such states through

347 the integrated management of disturbances such as herbivory and fire is therefore of key 
importance for the conservation of diverse forest understory flora (Royo \& Carson 2006;

349 Wisdom et al. 2006).

350 Can effects on dominance always be used to predict the outcome of fire-browsing 351 interactions?

352 We were able to predict the outcome of the fire-browsing interaction in our study. However, 353 this was most likely due to the particularities of our study system rather than a predictability 354 of fire-browsing interactions in general. In our study system, the most dominant and 355 widespread understory species is $P$. esculentum, which is of low palatability (Di Stefano \& 356 Newell 2008) and responds positively to fire (Spencer \& Baxter 2006). Therefore, both fire and browsing acted to increase the dominance of $P$. esculentum, and their functionallymoderated effects were synergistic. In addition, fire increased browsing activity, meaning that the numerically-mediated interaction between fire and browsing also had positive synergistic 360 effects.

By contrast, in many other systems, the outcomes of fire-browsing interactions will be

362 far less predictable. For example, in a system where fire and browsing act antagonistically

363 (e.g. fire increases dominance, but browsing has the opposite effect, as in Eby et al. 2014),

364 where more than one species is dominant (and fire or browsing responses differ between

365 these species) and/or where functionally-moderated effects are in opposition to numerically-

366 mediated effects, the outcome will depend on the balance of these opposing effects. Further,

367 fire and browsing may interact in more subtle ways, such as modifying the strength of each

368 other's effects on dominant species. For example, the tissues of plants regenerating after fire

369 often lack the physical and chemical defences of mature plants, meaning generally

370 unpalatable plants can be highly palatable after burning (Augustine \& McNaughton 1998). If

371 differences in palatability between species are reduced, herbivores feed less selectively, so 372 the strength of browsing effects on assemblage dominance can be reduced or even eliminated 
373 (Augustine \& McNaughton 1998). In addition, low severity fires, such as prescribed burns

374 can have different effects on the plant community than high severity fires that often occur as

375 wildfire (Morrison 2002). Different fire severities may therefore have differing effects on

376 dominant species, and so the outcomes of fire-browsing interactions are likely to vary with

377 fire severity. Therefore, predicting the outcome of fire-browsing interactions will only be

378 possible in some ecosystems, and where there is detailed knowledge of the palatability and

379 functional traits of plant species. Outside of these systems, manipulative experiments will

380 continue to be critical to improving understanding of the dynamics of fire-browsing

381 interactions.

\section{Conclusion}

383 In forested systems that are dominated by unpalatable, fire-resistant plant species, prescribed

384 fire and browsing are likely to interact synergistically to increase assemblage dominance and

385 reduce plant community diversity. In such systems, integrated management of fire and large

386 herbivores will be necessary to prevent the development of an understory dominated by a

387 narrow set of fire tolerant, unpalatable species. In forested ecosystems where unpalatable, fire

388 resistant species are not dominant, the outcome of fire-browsing interactions will not be so

389 easy to predict. Therefore manipulative studies which can examine both the individual and

390 interactive effects of these disturbances, and their interaction pathways, will continue to play

391 a central role in developing our understanding of fire-browsing interactions in forest

392 ecosystems.

\section{Acknowledgements}

395 Staff of BNP conducted prescribed burns. We thank the Department of Environment and the

396 landowners and co-managers of BNP - the Wreck Bay Aboriginal Community for supporting 
this project. The Margaret Middleton Fund, The Norman Wettenhall Foundation and the

Long Term Ecological Research Network provided financial support.

399

$400 \quad$ Literature Cited

401

402

403

404

405

406

407

408

409

410

411

412

413

414

415

416

417

418

419

420

Allred, B.W., Fuhlendorf, S.D., Engle, D.M. \& Elmore, R.D. 2011. Ungulate preference for burned patches reveals strength of fire-grazing interaction. Ecology and Evolution 1: 132-144.

Arthur, A.D., Catling, P. \& Reid, A. 2012. Relative influence of habitat structure, species interactions and rainfall on the post-fire population dynamics of ground-dwelling vertebrates. Austral Ecology 37: 958-970.

Augustine, D.J. \& McNaughton, S.J. 1998. Ungulate effects on the functional species composition of plant communities: Herbivore selectivity and plant tolerance. Journal of Wildlife Management 62: 1165-1183.

Barton, K. 2014. MuMIn: Multi-model inference.R package version 1.10.5., http://CRAN.Rproject.org/package=MuMIn.

Boer, M.M., Sadler, R.J., Wittkuhn, R.S., McCaw, L. \& Grierson, P.F. 2009. Long-term impacts of prescribed burning on regional extent and incidence of wildfiresEvidence from 50 years of active fire management in SW Australian forests. Forest Ecology and Management 259: 132-142.

Borer, E.T., Seabloom, E.W., Gruner, D.S., Harpole, W.S., Hillebrand, H., Lind, E.M. (...) \& Yang, L.H. 2014. Herbivores and nutrients control grassland plant diversity via light limitation. Nature 508: 517-520.

Burnham, K.P. \& Anderson, D.R. 2002. Model selection and multimodel inference: a practical information-theoretic approach. 2nd ed. Springer-Verlag, New York. 
421 Collins, S.L. \& Calabrese, L.B. 2012. Effects of fire, grazing and topographic variation on vegetation structure in tallgrass prairie. Journal of Vegetation Science 23: 563-575.

423

424

425

426

427

428

429

430

431

432

433

434

435

436

437

438

439

440

441

442

443

Côté, S.D., Beguin, J., de Bellefeuille, S., Champagne, E., Thiffault, N. \& Tremblay, J.P. 2014. Structuring effects of deer in boreal forest ecosystems. Advances in Ecology 2014: Article ID: 917834.

Côté, S.D., Rooney, T.P., Tremblay, J.P., Dussault, C. \& Waller, D.M. 2004. Ecological impacts of deer overabundance. Annual Review of Ecology, Evolution and Systematics 35: 113-147.

Davis, N.E., Coulson, G. \& Forsyth, D.M. 2008. Diets of native and introduced mammalian herbivores in shrub-encroached grassy woodland, south-eastern Australia. Wildlife Research 35: 684-694.

De Cáceres, M. \& Legendre, P. 2009. Associations between species and groups of sites: indices and statistical inference. Ecology 90: 3566-3574.

De Cáceres, M., Legendre, P. \& Moretti, M. 2010. Improving indicator species analysis by combining groups of sites. Oikos 119: 1674-1684.

de la Cretaz, A. \& Kelty, M. 1999. Establishment and control of hay-scented Fern: A native invasive species. Biological Invasions 1: 223-236.

Dexter, N., Hudson, M., James, S., MacGregor, C. \& Lindenmayer, D.B. 2013. Unintended consequences of invasive predator control in an Australian forest: Overabundant wallabies and vegetation change. PloS ONE 8: e69087.

Dexter, N., Ramsey, D.L., MacGregor, C. \& Lindenmayer, D. 2012. Predicting ecosystem wide impacts of wallaby management using a fuzzy cognitive map. Ecosystems 15: 1363-1379. 
Di Stefano, J. \& Newell, G.R. 2008. Diet selection by the swamp wallaby (Wallabia bicolor): Feeding strategies under conditions of changed food availability. Journal of Mammalogy 89: 1540-1549.

Didham, R.K., Tylianakis, J.M., Gemmell, N.J., Rand, T.A. \& Ewers, R.M. 2007. Interactive effects of habitat modification and species invasion on native species decline. Trends in Ecology \& Evolution 22: 489-496.

Dufrene, M. \& Legendre, P. 1997. Species assemblages and indicator species: the need for a flexible asymmetrical approach. Ecological Monographs 67.

Eby, S., Burkepile, D., Fynn, R.S., Burns, C., Govender, N., Hagenah, N. (...) \& Smith, M. 2014. Loss of a large grazer impacts savanna grassland plant communities similarly in North America and South Africa. Oecologia 175: 293-303.

Fisher, J.T. \& Wilkinson, L. 2005. The response of mammals to forest fire and timber harvest in the North American boreal forest. Mammal Review 35: 51-81.

Fletcher, M.T., Brock, I.J., Reichmann, K.G., McKenzie, R.A. \& Blaney, B.J. 2011. Norsesquiterpene glycosides in bracken ferns (Pteridium esculentum and Pteridium aquilinum subsp. wightianum) from eastern Australia: Reassessed poisoning risk to animals. Journal of Agricultural and Food Chemistry 59: 5133-5138.

Fuhlendorf, S.D., Harrell, W.C., Engle, D.M., Hamilton, R.G., Davis, C.A. \& Leslie Jr, D.M. 2006. Should heterogeneity be the basis for conservation? Grassland bird response to fire and grazing. Ecological Applications 16: 1706-1716.

Garvey, N., Ben-Ami, D., Ramp, D. \& Croft, D.B. 2010. Survival behaviour of swamp wallabies during prescribed burning and wildfire. Wildlife Research 37: 1-12.

Gelman, A. \& Hill, J. 2007. Data analysis using regression and multilevel/hierarchical models. Cambridge University Press, Cambridge, UK. 
Harrison, X.A. 2014. Using observation-level random effects to model overdispersion in count data in ecology and evolution. PeerJ 2: e616.

Hester, A.J., Bergman, M., Iason, G.R. \& Moen, J. 2006. Impacts of large herbivores on plant community structure and dynamics. In: Danell, K., Bergström, R., Duncan, P. \& Pastor, J. (eds.) Large Herbivore Ecology, Ecosystem Dynamics and Conservation, pp. 97-141. Cambridge University Press, Cambridge.

Hester, A.J., Edenius, L., Buttenschon, R.M. \& Kuiters, A.T. 2000. Interactions between forests and herbivores: The role of controlled grazing experiments. Forestry 73: 381391.

Hidding, B., Tremblay, J.-P. \& Côté, S.D. 2013. A large herbivore triggers alternative successional trajectories in the boreal forest. Ecology 94: 2852-2860.

Holm, J.A., Thompson, J.R., McShea, W.J. \& Bourg, N.A. 2013. Interactive effects of chronic deer browsing and canopy gap disturbance on forest successional dynamics. Ecosphere 4: art144.

Horsley, S.B., Stout, S.L. \& deCalesta, D.S. 2003. White-tailed deer impact on the vegetation dynamics of a northern hardwood forest. Ecological Applications 13: 98-118.

Jenkins, L.H., Jenkins, M.A., Webster, C.R., Zollner, P.A. \& Shields, J.M. 2014. Herbaceous layer response to 17 years of controlled deer hunting in forested natural areas. Biological Conservation 175: 119-128.

Kerns, B.K., Buonopane, M., Thies, W.G. \& Niwa, C. 2011. Reintroducing fire into a ponderosa pine forest with and without cattle grazing: understory vegetation response. Ecosphere 2: art59.

Kirby, K.J. 2001. The impact of deer on the ground flora of British broadleaved woodland. Forestry 74: 219-229. 
492 Koerner, S.E., Burkepile, D.E., Fynn, R.W.S., Burns, C.E., Eby, S., Govender, N. (...) \& Smith, M.D. 2014. Plant community response to loss of large herbivores differs between North American and South African savanna grasslands. Ecology 95: 808816.

Koerner, S.E. \& Collins, S.L. 2014. Interactive effects of grazing, drought, and fire on grassland plant communities in North America and South Africa. Ecology 95: 98-109.

Lindenmayer, D., MacGregor, C., Dexter, N., Fortescue, M. \& Beaton, E. 2014. Booderee National Park, The Jewel of Jervis Bay. CSIRO Publishing, Collingwood, Australia.

Lindenmayer, D.B., MacGregor, C., Welsh, A., Donnelly, C., Crane, M., Michael, D. (...) \& Gill, A.M. 2008. Contrasting mammal responses to vegetation type and fire. Wildlife Research 35: 395-408.

Magurran, A.E. 2004. Measuring Biological Diversity. Blackwell Publishing, Oxford, UK.

Mathisen, K.M., Buhtz, F., Danell, K., Bergström, R., Skarpe, C., Suominen, O. \& Persson, I.L. 2010. Moose density and habitat productivity affects reproduction, growth and species composition in field layer vegetation. Journal of Vegetation Science 21: 705716.

McCune, B. \& Grace, J.B. 2002. Analysis of Ecological Communities. MjM Software Design, Gleneden Beach, Oregon, USA.

McCune, B. \& Mefford, B.M.J. 2006. PC-ORD. Multivariate analysis of ecological data.Version 5.10. MjM Software, Gleneden Beach, Oregon, U.S.A.

McFarland, D.C. 1998. Fire and the vegetation composition of subtropical heathlands in south-eastern Queensland. Australian Journal of Botany 36: 533-546.

Milchunas, D.G., Sala, O.E. \& Lauenroth, W.K. 1988. A generalized model of the effects of grazing by large herbivores on grassland community structure. American Naturalist 132: $87-106$. 
517 Morrison, D.A. 2002. Effects of fire intensity on plant species composition of sandstone 518 communities in the Sydney region. Austral Ecology 27: 433-441.

519 Pinheiro, J. \& Bates, D. 2000. Mixed-Effects Models in S and S-PLUS. Springer-Verlag, New $520 \quad$ York, NY

521 R Core Team 2013. A language and environment for statistical computing. R Foundation for 522 Statistical Computing, Vienna, Austria. URL http://www.R-project.org/.

523 Raffaele, E., Veblen, T.T., Blackhall, M. \& Tercero-Bucardo, N. 2011. Synergistic influences of introduced herbivores and fire on vegetation change in northern Patagonia, Argentina. Journal of Vegetation Science 22: 59-71.

Robinson, L. 1991. Field guide to the native plants of Sydney. Kangaroo Press, Kenthurst, NSW, Australia.

Rooney, T.P. 2001. Deer impacts on forest ecosystems: a North American perspective. Forestry 74: 201-208.

Rooney, T.P. 2009. High white-tailed deer densities benefit graminoids and contribute to biotic homogenization of forest ground-layer vegetation. Plant Ecology 202: 103-111.

Rooney, T.P. \& Waller, D.M. 2003. Direct and indirect effects of white-tailed deer in forest ecosystems. Forest Ecology and Management 181: 165-176.

Royo, A.A. \& Carson, W.P. 2006. On the formation of dense understory layers in forests worldwide: consequences and implications for forest dynamics, biodiversity, and succession. Canadian Journal of Forest Research 36: 1345-1362.

Royo, A.A., Collins, R., Adams, M.B., Kirschbaum, C. \& Carson, W.P. 2010a. Pervasive interactions between ungulate browsers and disturbance regimes promote temperate forest herbaceous diversity. Ecology 91: 93-105. 
540 Royo, A.A., Stout, S.L., de Calesta, D.S. \& Pierson, T.G. 2010b. Restoring forest herb communities through landscape-level deer herd reductions: Is recovery limited by legacy effects? Biological Conservation 143: 2425-2434.

Skre, O., Wielgolaski, F.E. \& Moe, B. 1998. Biomass and chemical composition of common forest plants in response to fire in western Norway. Journal of Vegetation Science 9: 501-510.

Spencer, R.-J. \& Baxter, G.S. 2006. Effects of fire on the structure and composition of open eucalypt forests. Austral Ecology 31: 638-646.

Stephens, S.L. \& Ruth, L.W. 2005. Federal forest-fire policy in the United States. Ecological Applications 15: 532-542.

Tanentzap, A.J., Bazely, D.R., Koh, S., Timciska, M., Haggith, E.G., Carleton, T.J. \& Coomes, D.A. 2011. Seeing the forest for the deer: Do reductions in deer-disturbance lead to forest recovery? Biological Conservation 144: 376-382.

Taws, N. 1998. Fire and vegetation management in Jervis Bay Territory, Report. Environment Australia, Canberra.

Tolhurst, K.G. \& Turvey, N.D. 1992. Effects of bracken (Pteridium esculentum (forst. f.) Cockayne) on eucalypt regeneration in west-central Victoria. Forest Ecology and Management 54: 45-67.

Tremblay, J.-P., Huot, J. \& Potvin, F. 2006. Divergent nonlinear responses of the boreal forest field layer along an experimental gradient of deer densities. Oecologia 150: 78-

Tylianakis, J.M., Didham, R.K., Bascompte, J. \& Wardle, D.A. 2008. Global change and species interactions in terrestrial ecosystems. Ecology Letters 11: 1351-1363. 

292.

567 Zuur, A.F., Ieno, E.N., Walker, N.J., Saveliev, A.A. \& Smith, G.M. 2009. Mixed effects

568 models and extensions in ecology with $R$. Springer, New York, USA.

569

570 
571 Supporting Information

572 Additional supporting information may be found in the online version of this article:

573 Appendix S1. Plant species list

574 Appendix S2. Tables of model rankings 
576 Table 1. Estimates of coefficients (Est.), their standard errors (SE) and probabilities for the top-ranked linear mixed model testing the effects of

577 fire (burnt or unburnt), large herbivore activity (scats per $100 \mathrm{~m}^{2}$, ln transformed), time since fire (3, 9,15 or 21 months) on plant species richness

578 (species $/ 36 \mathrm{~m}^{2}$ ), diversity (Simpson's reciprocal index, $1 / D$ ), evenness (Simpson's evenness, $E_{1 / D}$ ) and dominance (Berger-Parker, $d$ ). Pre-

579 treatment values were included as a fixed effect to account for pre-existing differences between sites. Reference states for comparisons were

580 unburnt sites three months post-fire. Random terms for each model were block/site.

\begin{tabular}{|c|c|c|c|c|c|c|c|c|c|c|c|c|c|c|c|c|c|}
\hline \multirow{2}{*}{\multicolumn{2}{|c|}{ Fixed effects }} & \multicolumn{4}{|c|}{ Species richness } & \multicolumn{4}{|c|}{ Diversity $(1 / D)$} & \multicolumn{4}{|c|}{ Evenness $\left(E_{1 / D}\right)$} & \multicolumn{4}{|c|}{ Dominance $(d)$} \\
\hline & & Est. & SE & $\mathrm{df}$ & $P$ & Est. & SE & $\mathrm{df}$ & $P$ & Est. & SE & $\mathrm{df}$ & $P$ & Est. & SE & $\mathrm{df}$ & $P$ \\
\hline \multicolumn{2}{|l|}{ Intercept } & 6.15 & 5.33 & 66 & 0.253 & 2.25 & 0.72 & 64 & 0.003 & 0.075 & 0.024 & 64 & 0.002 & 0.266 & 0.078 & 67 & 0.001 \\
\hline \multicolumn{2}{|c|}{ Pre-treatment value } & 0.85 & 0.19 & 18 & $<0.001$ & 0.39 & 0.20 & 18 & 0.060 & 0.373 & 0.168 & 18 & 0.040 & 0.296 & 0.126 & 18 & 0.030 \\
\hline \multicolumn{2}{|c|}{ Fire } & -9.40 & 1.45 & 18 & $<0.001$ & 1.04 & 0.53 & 18 & 0.066 & 0.095 & 0.020 & 18 & $<0.001$ & 0.107 & 0.031 & 18 & 0.003 \\
\hline \multicolumn{6}{|c|}{ Herbivores (In transformed) } & 0.28 & 0.48 & 64 & 0.558 & 0.012 & 0.016 & 64 & 0.455 & -0.022 & 0.046 & 67 & 0.636 \\
\hline \multirow[t]{3}{*}{ Time since fire } & 9 months & 0.50 & 0.78 & 66 & 0.523 & -0.43 & 0.48 & 64 & 0.378 & -0.016 & 0.020 & 64 & 0.410 & 0.115 & 0.038 & 67 & 0.003 \\
\hline & 15 months & -0.25 & 0.78 & 66 & 0.749 & -0.02 & 0.48 & 64 & 0.973 & 0.001 & 0.020 & 64 & 0.975 & 0.063 & 0.038 & 67 & 0.100 \\
\hline & 21 months & 1.17 & 0.78 & 66 & 0.139 & 0.13 & 0.49 & 64 & 0.785 & 0.001 & 0.020 & 64 & 0.973 & 0.053 & 0.039 & 67 & 0.177 \\
\hline \multicolumn{2}{|c|}{ Fire:Herbivores(In) } & & & & & -1.68 & 0.64 & 64 & 0.011 & -0.059 & 0.021 & 64 & 0.006 & 0.209 & 0.061 & 67 & 0.001 \\
\hline \multirow[t]{3}{*}{ Fire:Time } & $\mathrm{B}: 9 \mathrm{~m}$ & 6.67 & 1.10 & 66 & $<0.001$ & -1.69 & 0.67 & 64 & 0.014 & -0.110 & 0.028 & 64 & $<0.001$ & & & & \\
\hline & $\mathrm{B}: 15 \mathrm{~m}$ & 10.33 & 1.10 & 66 & $<0.001$ & -1.88 & 0.67 & 64 & 0.007 & -0.126 & 0.028 & 64 & $<0.001$ & & & & \\
\hline & $\mathrm{B}: 21 \mathrm{~m}$ & 10.92 & 1.10 & 66 & $<0.001$ & -1.67 & 0.69 & 64 & 0.018 & -0.122 & 0.028 & 64 & $<0.001$ & & & & \\
\hline
\end{tabular}


581 Table 2. Results of generalised linear mixed models testing whether fire affected the level of

582 herbivore activity (scats per $100 \mathrm{~m}^{2}$ ) in the different exclosure treatments (open or partial

583 exclosure) through time $(3,9,15$ or 21 months post-fire). Full exclosure treatments were not

584 included in this analysis due to very low values $(\overline{\mathrm{X}}=1.78 \pm 0.53)$. Reference states for

585 comparisons were unburnt, open sites three months post-fire.

\begin{tabular}{|c|c|c|c|c|c|c|c|c|c|}
\hline \multirow[b]{2}{*}{ Fixed effects } & & \multicolumn{4}{|c|}{ Top ranked model } & \multicolumn{4}{|c|}{ Second ranked model } \\
\hline & & Est. & SE & $\mathrm{Z}$ & $P$ & Est. & SE & $\mathrm{Z}$ & $P$ \\
\hline \multicolumn{2}{|l|}{ Intercept } & 4.26 & 0.23 & 18.8 & $<0.001$ & 4.36 & 0.25 & 17.2 & $<0.001$ \\
\hline \multicolumn{2}{|l|}{ Fire } & 0.46 & 0.20 & 2.2 & 0.025 & 0.27 & 0.33 & 0.8 & 0.408 \\
\hline \multicolumn{2}{|c|}{ Exclosure (partial) } & -1.63 & 0.20 & -8.0 & $<0.001$ & -1.63 & 0.20 & -8.1 & $<0.001$ \\
\hline \multirow{3}{*}{ Time since fire } & 9 months & -0.51 & 0.24 & -2.1 & 0.038 & -1.04 & 0.32 & -3.2 & 0.001 \\
\hline & 15 months & -0.25 & 0.24 & -1.0 & 0.306 & -0.20 & 0.31 & -0.7 & 0.515 \\
\hline & 21 months & -0.89 & 0.24 & -3.6 & $<0.001$ & -0.81 & 0.31 & -2.6 & 0.010 \\
\hline \multirow[t]{3}{*}{ Fire:Time } & $B: 9 m$ & & & & & 1.01 & 0.44 & 2.3 & 0.022 \\
\hline & $\mathrm{B}: 15 \mathrm{~m}$ & & & & & -0.09 & 0.43 & -0.2 & 0.831 \\
\hline & $B: 21 \mathrm{~m}$ & & & & & -0.18 & 0.44 & -0.4 & 0.690 \\
\hline
\end{tabular}




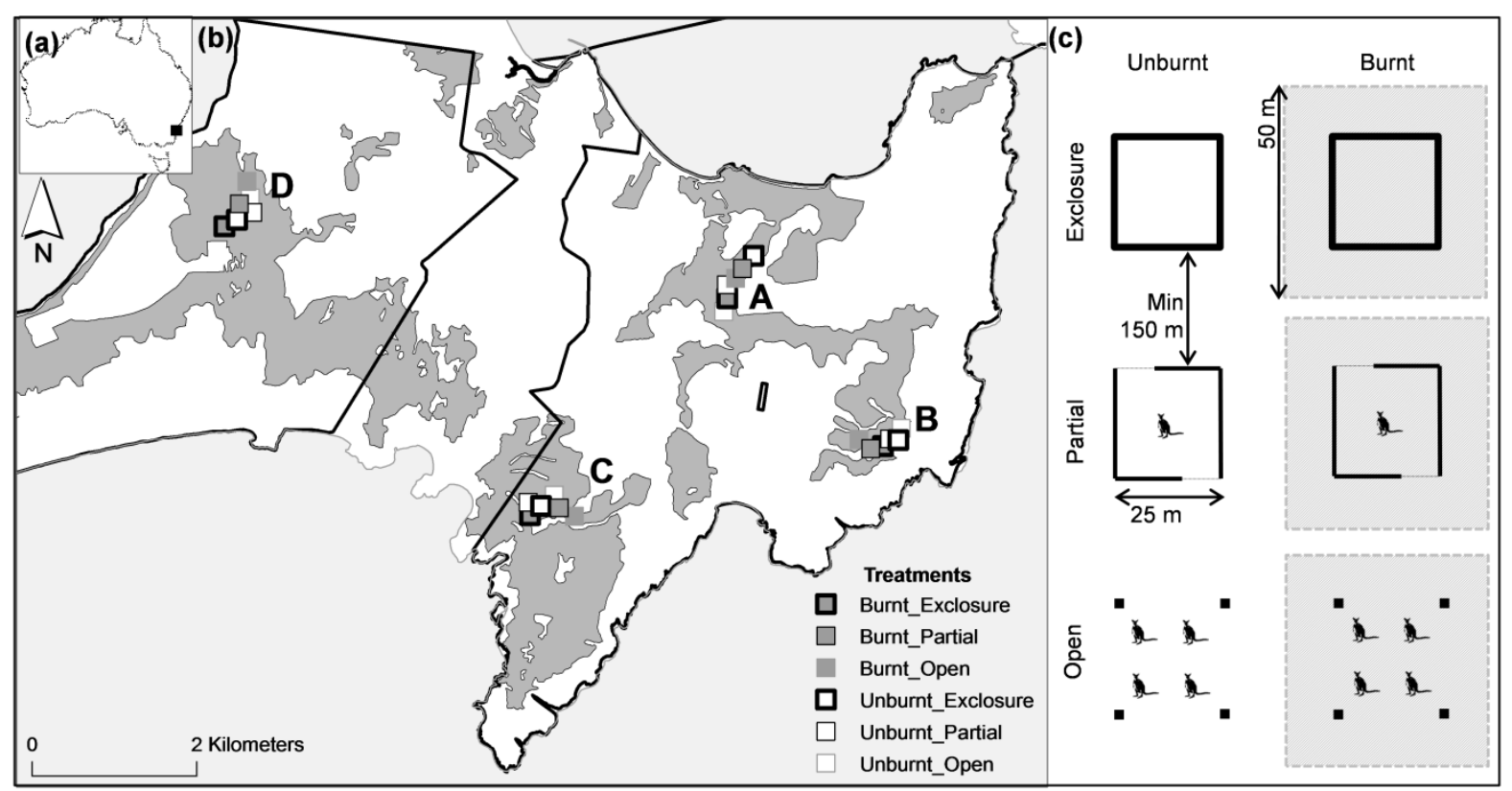

590 Figure 1. Study location and design showing (a) location of Booderee National Park in south-

591 eastern Australia, (b) location of the four experimental blocks (A-D) within Booderee

592 National Park, and (c) a schematic diagram of the factorial design showing the experimental

593 treatments and their arrangement within the four experimental blocks (not to scale, exact

594 spatial arrangement of sites varies between blocks). Dark grey shaded area in (b) shows the

595 extent of the Eucalyptus pilularis forest type within BNP, black outline indicates park

596 boundary, light grey shading depicts ocean. 

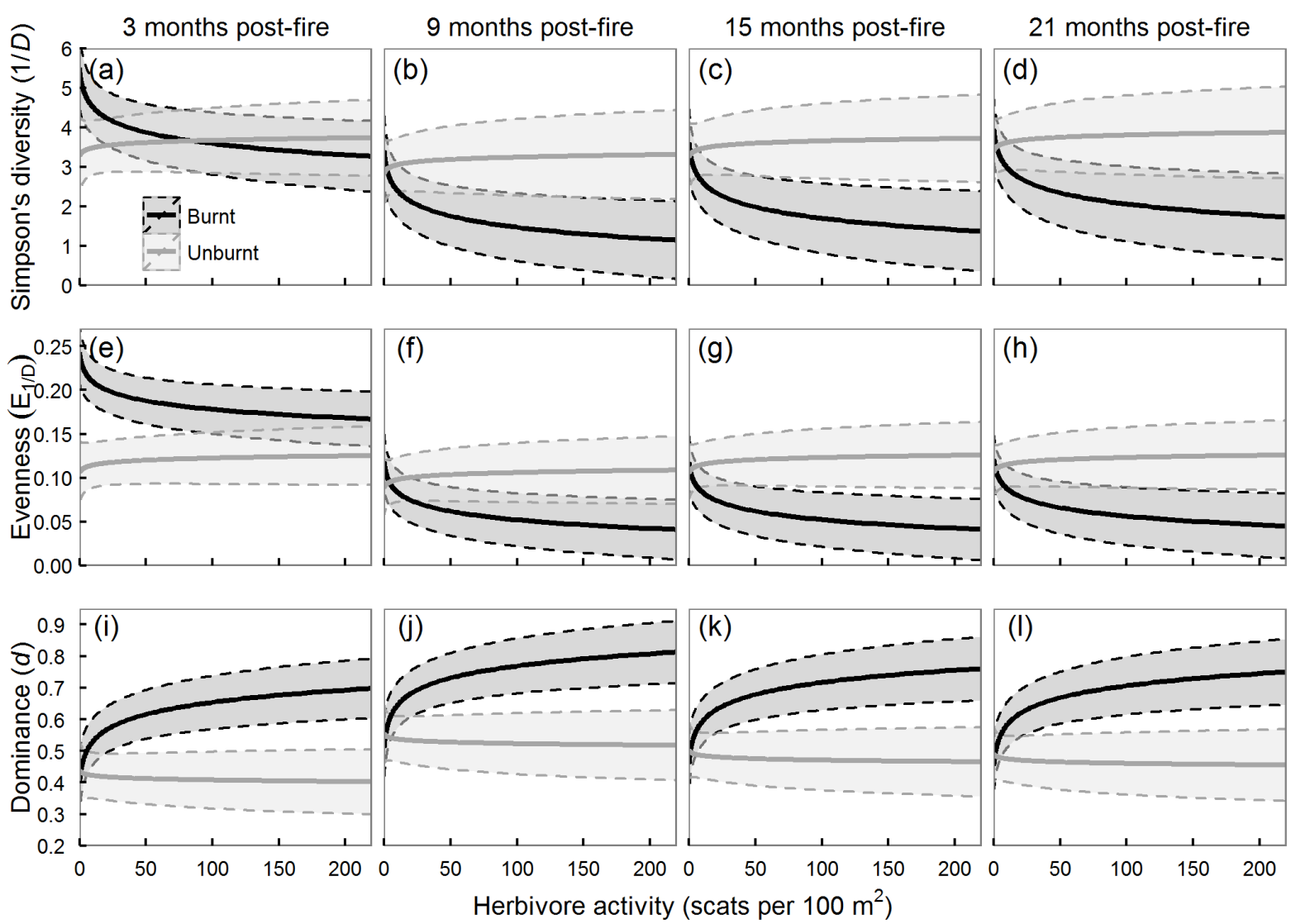

600

Figure 2. Response of plant community diversity (Simpson's reciprocal index, $1 / D$, a-d),

602 evenness (Simpson's evenness, $E_{1 / D}$, e-h) and dominance (Berger-Parker, $d$, i-1) to fire (burnt

603 or unburnt) and herbivore activity through time. Values are predicted means and $95 \%$

604 confidence intervals from the top-ranked model for each metric. Pre-treatment values were

605 fixed at the mean for all predictions (3.15 for diversity, 0.106 for evenness and 0.53 for 606 dominance).

607 

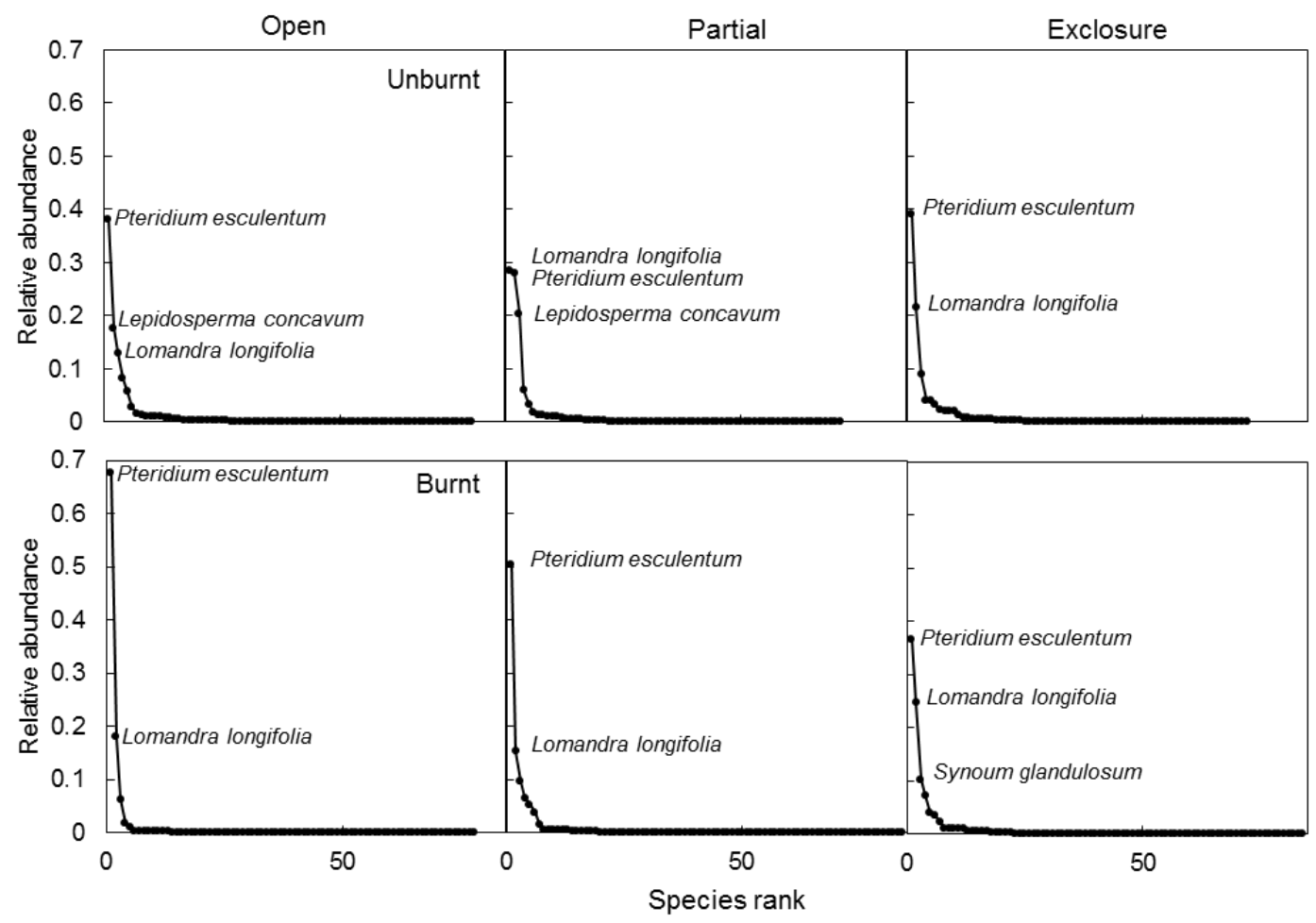

608

609 Figure 3. Species rank-abundance curves for burnt and unburnt sites under each of the

610 herbivory treatments in the final survey period (May 2014). Species with relative abundances

$611>0.1$ are identified on each plot.

612 

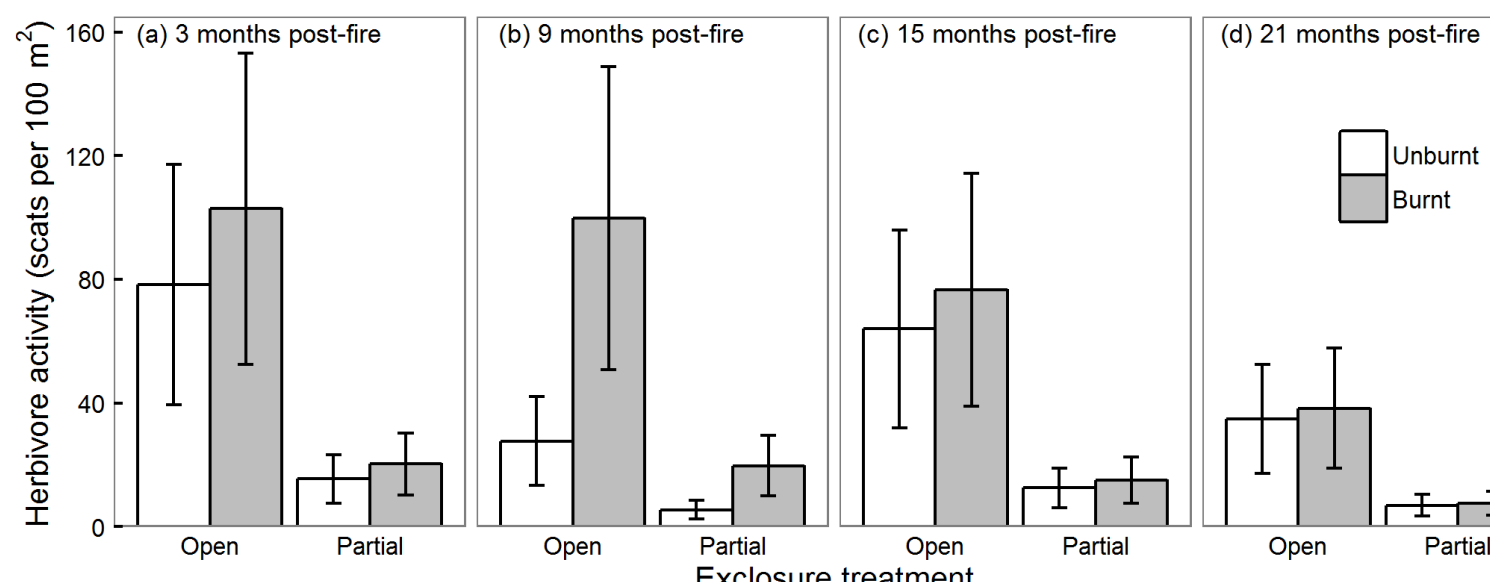

613

Exclosure treatment

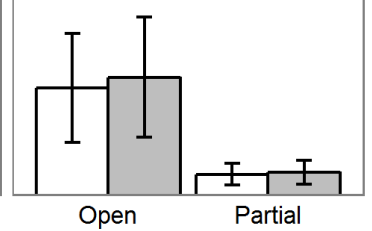

614 Figure 4. Herbivore activity in each of the experimental treatment combinations over time.

615 Values are the predicted mean scat count and $95 \%$ confidence intervals based on the second-

616 ranked generalised linear model. Full exclosure treatments were not included in this analysis

617 due to very low values $(\overline{\mathrm{x}}=1.78 \pm 0.53)$. 